\title{
Comparative Clinical Trial of Fluoridated Varnishes with Calcium Compounds to Prevent and Reverse Incipient Carious Lesions in School Children
}

\author{
Professor Juarez-Lopez Maria Lilia Adriana, PhD \\ Professor Marin Miranda Miriam, PhD \\ FES Zaragoza National Autonomus University of Mexico
}

Professor Molina Frechero Nelly, PhD

UAM Autonomus Metropolitan University

Doi:10.19044/esj.2020.v16n18p93 ～URL:http://dx.doi.org/10.19044/esj.2020.v16n18p93

\begin{abstract}
Objective: This paper focuses on comparing the clinical effectiveness of two fluoridated varnishes enhanced with calcium compounds to prevent and reverse incipient carious lesions (ICL). Method: A clinical study was carried out with 156 children aged 7-9 years. They were distributed into three groups for the topical application of: a) a sodium fluoride varnish with caseinphosphopeptide-amorphous-calcium-phosphate (CPP-ACP/NaF); b) a sodium fluoride varnish with phosphate-tri-calcium (NaF-TCP); c) a control. The application were every six months Caries Protective fraction (PF) which was obtained from Epidemiological indexes. Also, 2594 dental surfaces with caries free and incipient caries lesions (ICL) were followed up after 18 months. ANOVA repeated measures were carried out, and McNemar and Gamma tests were also performed. Results: The DMFS values after treatments showed the following: a) $1.9 \pm 4$, b) $2.5 \pm 2$, and c) $3.1 \pm 4.8(\mathrm{p}=0.17$ ) with PF of $38 \%$ and $18 \%$ for groups $\mathrm{CPP}-\mathrm{ACP} / \mathrm{NaF}$ and $\mathrm{NaF}-\mathrm{TCP}$, respectively. ICL showed a reversal in 26.6\% (IC95: 17-35) of the CPP-ACP/NaF group, 24.6\% (IC95: 14-33) in the NaF-TCP group, and 23\% (IC95: 13-32) in the control group.. The percentage of free caries and incipient caries teeth were higher for CPP$\mathrm{ACP} / \mathrm{F}$ than control group. $\mathrm{p}=0.001$. Conclusion: Varnishes with calcium compounds promoted the recovery of ICL. However, CPP-ACP/NaF showed a better protective factor.
\end{abstract}

Keywords: Fluoride Varnish, Calcium Compound, Incipient Caries Lesion

\section{Introduction}

White spot lesions are the first indication of minimal loss of minerals in the dynamic physicochemical caries process. As the incipient caries lesion 
advances, the superficial enamel surface collapses, causing a cavity (Fearsthone, 2012). Thus, early detection and minimally invasive preventive treatment are required to prevent or reverse early caries lesions (Chen, 2010). Fluoride products have shown benefits in the prevention of dental caries as they inhibit demineralization, alter the metabolism of microorganisms present in biofilms, and promote remineralization. Fluor $(\mathrm{F})$ varnishes reduce the incidence of caries by $46 \%$, and children tolerate their application best among other F products used for this purpose (Marinho, 2013). However, their capacity to promote the recovery of incipient lesions is limited by the bioavailability of mineral ions in saliva and on dental surfaces. F varnishes contain 22,600 ppm F and calcium compounds have been added to them in recent years to potentiate their effect, and their activity has been proven mainly in in vitro (Espinosa, 2014; Cochrane, 2012). Among these compounds are casein phosphopeptide amorphous calcium phosphate (CPP-ACP) and phosphate tri-calcium (TCP).

CPP-ACP is derived from casein, which is a phosphoprotein of milk with an amorphous union of calcium and phosphate. Additionally, this compound is soluble and easily liberated and can neutralize acidic $\mathrm{pH}$ values, reduce bacterial growth, and hydrolyze hydroxyapatite which facilitates the remineralization of incipient carious lesions (Nongonierma, 2012; Alamoudi, 2013).

TCP has a structure similar to hydroxyapatite and is surrounded by carboxylic acid. It facilitates the slowing of calcium, phosphate, and $\mathrm{F}$ ion chelation on dental surfaces. Furthermore, TCP increases the microhardness of enamel and makes the surface become more resistant to acid attack (Clinpro \& Thimmaiah, 2019).

In our community, children aged 6-9 years have an average of 3.8 primary teeth and 0.7-1.3 permanent teeth affected by caries. The index of decayed, missing, and filled permanent teeth (DMFT) at 10 years was 2.9. (SIVEPAB, 2015). Therefore, in elementary schools, caries prevalence remains high. Hence, the aim of this study was to evaluate a caries prevention school program and compare the effectiveness of two different fluoride varnishes on the arrest or regression of carious lesions in their early stages after 18 months of follow up.

\section{Methods}

A randomized trial was conducted in accordance with guidelines laid out in the Declaration of Helsinki. It met the ethical regulations and was approved by the university's research committee. After authorization by the elementary school authorities, the parents of the children were informed about the study's characteristics and the benefits of the treatments. Furthermore, they were advised that they were free to terminate their children's participation in 
the study at any time. Only school children whose parents returned the signed consent forms were enrolled. This study has been designed to conform with the CONSORT guidelines (Butcher, 2019).

\section{Sample Size}

The convenience sample comprised of healthy children aged seven to nine years at a public elementary school. The prevention program was carried out between September 2017 to May 2019. A total of 171 school children agreed to participate at the beginning of the clinical trial, but 15 school children were excluded from the final evaluation because they did not comply with the treatments. Hence, only 156 school children were included in the final evaluation, with a total of 2594 dental surfaces caries-free or with incipient caries lesions at baseline, who were followed up for 18 months

\section{Participants}

The eligibility criteria indicated that the school children should have one or more incipient caries lesions. Patients with systemic disease, syndromic abnormalities, hypoplastic dental lesions, and milk protein allergies were excluded from the study.

\section{Study Protocol}

Two experienced pediatric dentists examined each child with no. 5 mirrors and rounded-point probes of $0.5 \mathrm{~mm}$ diameter to determine caries lesions and assess the presence of dental biofilms. Before the clinical examination, the two dentists received calibration training. The first one was trained on the epidemiological O'Leary plaque index ${ }^{13}$ (O'Leary, 1972) and caries index of decayed, missing, and filled permanent teeth and surfaces (DMFT and DMFS) with $\kappa=0.83$. The second one received a calibration $(\kappa=$ 0.76) in the International Caries Detection and Assessment System (ICDAS) criteria (Braga, 2009; Pitts, 2013). ${ }^{14-16}$ Surfaces of primary and permanent molars were also selected with 0,1 y 2 ICDAS criteria .. The calibration was carried out after double examinations on thirty children of another school and supervised by an epidemiological expert examiner.

For the clinical examination, the tooth surfaces were dried with air for $5 \mathrm{~s}$, and lesions at ICDAS 1 and 2 were considered incipient caries lesions (ICL). Interproximal surfaces were excluded from this study. The clinicians who conducted the clinical examinations were not informed about the treatment group to which the participants were assigned.

Before varnish application, all of the school children received dietary and hygiene counseling and monthly supervised tooth brushing. After the baseline diagnosis, the participants were randomly distributed into three groups-for the topical application every six months of: A) varnish of sodium 
fluoride with casein phosphopeptide, amorphous calcium phosphate (CPP$\mathrm{ACP} / \mathrm{NaF}$ ): $\mathrm{Mi}$ varnish $\mathrm{TM}$; $\mathrm{B}$ ) varnish of sodium fluoride with tri calcium phosphate (NaF-TCP): ClinproTM®; and C) no varnish (control group). The treatments were applied after brushing the teeth and at least two hours before recess to ensure that the children did not eat any food after the varnish application.After treatments, in the final clinical examinations of the molars surfaces, the ICDAS 3 criteria was also included for those cases in which surfaces became to dentine carious lesions.

\section{Statistical Method}

The data were analyzed using the SPSS statistical package (15.0). For quantitative data, the mean and standard deviation were calculated and comparisons were made using the ANOVA repeated measures test. The Caries Protective Fraction (PF) of each treatment was obtained by calculating the difference between the values of the DMFS index of the control group with respect to the values of each varnish group, which was divided by the control group index by 100 (Arruda, 2012). The surfaces caries free and incipient lesions were expressed by frequencies and percentages, while Wilcoxon and Mann-Whitney U-tests which compare qualitative variables were performed at a $5 \%$ level of significance.

\section{Results}

A total of 156 students completed the treatment, and $47 \%$ were boys while $53 \%$ were girls. Figure 1 shows the flow chart of the study and Table 1 shows the mean caries scores according to the WHO criteria before and after the treatments. Considering the DMFS values, the PF was $38 \%$ for the CPP$\mathrm{ACP} / \mathrm{NaF}$ varnish and $18 \%$ for the $\mathrm{NaF}-\mathrm{TCP}$ varnish

Table 2 shows the distribution of caries-free and incipient lesions surfaces that were followed up using the ICDAS criteria. The percentage of caries-free surfaces that remained healthy was higher in the CPP-ACP/NaF group (65\%; IC $95: 61-68$ ). The surfaces with incipient caries lesions at the baseline, after 18 months, showed a reversal in $26.6 \%$ (IC95: 17-35) in the CPP-ACP/NaF group, 24.6\% (IC $95: 14-33$ ) in the NaF-TCP group, and $23 \%$ (IC95: 13-32) in the control group. Similarly, Figure 1 shows only the follow up for incipient lesions after the treatments. The percentage of free caries and incipient caries teeth were higher for CPP-ACP/F than control group where $\mathrm{p}=0.001$. The figure also show the lesions that became dentine carious lesions after 18 months of follow up.

\section{Discussion}

One of the main challenges in pediatric dental practice is the implementation of strategies aimed at preserving dental health. Dental caries 
is the most frequent oral disease in children, which affects their quality of life. This is not only because it is an infectious and painful condition but also because it can alter function, sleep patterns, and behavior (Abanto, 2011). The results of this study agree with the application of fluoridated varnishes with calcium compounds in high-risk children as part of school programs, where the children may benefit from these enhanced varnishes at a low cost (Schwendicke, 2018). After 18 months, remineralization and retainment of incipient caries lesions in response to both fluoride varnishes was observed. However, significant differences with the control group were observed only in $\mathrm{CPP}-\mathrm{ACP} / \mathrm{NaF}$ group. Other studies have also noted that casein phosphopeptide-amorphous treatments reduce the progression of incipient carious lesions (Hug, 2016; Juárez-López, 2014).

CPP-ACP contains calcium phosphate, which facilitates stabilization by forming conglomerates that adhere to the dental biofilm and surfaces and acts as a reservoir. Furthermore, the casein phosphopeptides that was formed favor dental biomineralization, neutralize acidic $\mathrm{pH}$ values, and hinder bacterial growth. ACP also enhances the uptake of fluoride, resulting in the remineralization of demineralized enamel (Shemehorm, 2011).

On the other hand, the TCP varnish acts by adding calcium and phosphate ions to the enamel interface with an added fumaric barrier to allow for better ion release. Phosphate tri-calcium enhances the ion exchange at the tooth surface and protects them. Additionally, studies have demonstrated that the high microhardness of enamel surfaces treated with a functionalized form of TCP have a greater potential for remineralization under acidic conditions (Elkassas, 2014; Rirattanapong, 2014). Currently, other calcium compounds have been researched and added to varnishes such as TMT sodium trimetaphosphate and calcium glyceryl phosphate (CaGP). Walczak and Turska-Szybka (2017) in a systematic review recommend adding ACP to dental biomaterials for remineralization of incipient caries lesions as demonstrated in this study.

It is also important to promote preventive behaviors in home such as family education about oral health, mainly plaque removal. Furthermore, other non-invasive diagnostic and monitoring method such as transillumination of teeth with diagnocam are recommended (Ogodescu, 2017). Additionally, oral health programs at elementary schools need to combine the use of all available resources in order to facilitate the early detection of incipient lesions and the implementation of minimally invasive strategies to arrest and reverse the progression of new carious lesions.

\section{Conclusion}

After 18 months of clinical follow-up and within the limitations of this study, it is evident that the application of fluoride varnish enhanced with 
calcium compounds may be recommended as a part of integral strategies used for caries management for high-risk school children populations. In this study, both fluoridated varnishes with added calcium compounds were effective to prevent and remineralize incipient caries lesions. However, the one with CCP$\mathrm{ACP} / \mathrm{NaF}$ showed a better protective factor.

\section{Acknowledgment}

This work was supported by a grant from academic program 218915 . We also appreciate Dr. Martha A Sánchez Rodríguez for her contribution to the statistical analysis.

Table 1. O'Leary and Caries index in school children aged 7-9 years before and after undergoing fluoride varnishes enhanced with calcium compounds treatments.

\begin{tabular}{lllllr}
\hline & & CPP-ACP & NaF-TPC & Control & P* \\
\hline \multirow{2}{*}{ O'Leary } & $\begin{array}{l}\text { Baseline } \\
\text { Final }\end{array}$ & $79 \%$ & $73 \%$ & $76 \%$ & 0.06 \\
& & & $68 \%$ & $61 \%$ & 0.11 \\
DMFT & $\begin{array}{l}\text { Baseline } \\
\text { Final }\end{array}$ & $0.33 \pm 0.8$ & $0.42 \pm 0.9$ & $0.35 \pm 0.8$ & 0.98 \\
& $1.1 \pm 1.8$ & $1.6 \pm 1.6$ & $1.7 \pm 1.8$ & 0.41 \\
DMFS & $\begin{array}{l}\text { Baseline } \\
\text { Final }\end{array}$ & $0.39 \pm 0.9$ & $0.61 \pm 1.8$ & $0.34 \pm 0.7$ & 0.94 \\
& $1.9 \pm 4$ & $2.5 \pm 2$ & $3.1 \pm 4.8$ & 0.41 \\
\hline
\end{tabular}

DMFT: decayed, missing, and filled permanent teeth.

DMFS: decayed, missing, and filled permanent teeth surfaces.

*ANOVA repeated measures test, post hoc Dunnett

\begin{tabular}{|c|c|c|c|c|c|}
\hline Group & Before & After treat & & & \\
\hline \multirow[b]{2}{*}{$\begin{array}{l}C P P-A C P / F \\
N=921\end{array}$} & & $\begin{array}{c}C F \\
N(\%)\end{array}$ & $\begin{array}{l}I C L \\
N(\%)\end{array}$ & $\begin{array}{l}D C L \\
N(\%)\end{array}$ & $P^{*}$ \\
\hline & $\begin{array}{l}C F \\
N=564 \\
I C L \\
N=357\end{array}$ & $366(65)$ & $162(45.4)$ & $\begin{array}{l}82(14.5) \\
100(28)\end{array}$ & 0.001 \\
\hline \multirow{2}{*}{$\begin{array}{l}N a F-T C P \\
N \quad N=985\end{array}$} & $\begin{array}{l}C F \\
N=537\end{array}$ & $274(51)$ & $76(14.2)$ & $187(34.8)$ & \multirow[b]{2}{*}{0.001} \\
\hline & $\begin{array}{l}I C L \\
N=448\end{array}$ & $110(24.6)$ & $136(30.4)$ & 202(45) & \\
\hline \multirow[t]{2}{*}{$\begin{array}{c}\text { Control } \\
N=688\end{array}$} & $\begin{array}{l}C F \\
N=365\end{array}$ & $180(49.3)$ & $72(19.7)$ & $113(31)$ & \multirow[t]{2}{*}{0.001} \\
\hline & $\begin{array}{l}I C L \\
N=323\end{array}$ & $76(23.5)$ & $83(25.7)$ & $164(50.8)$ & \\
\hline
\end{tabular}

$\overline{\text { Table 2. Distribution of dental surfaces before and after fluoride varnishes enhanced }}$ with calcium compounds treatments

CF: caries free; ICL: Incipient carious lesion; DCL: Dentine carious lesion

* McNemar test within each group 


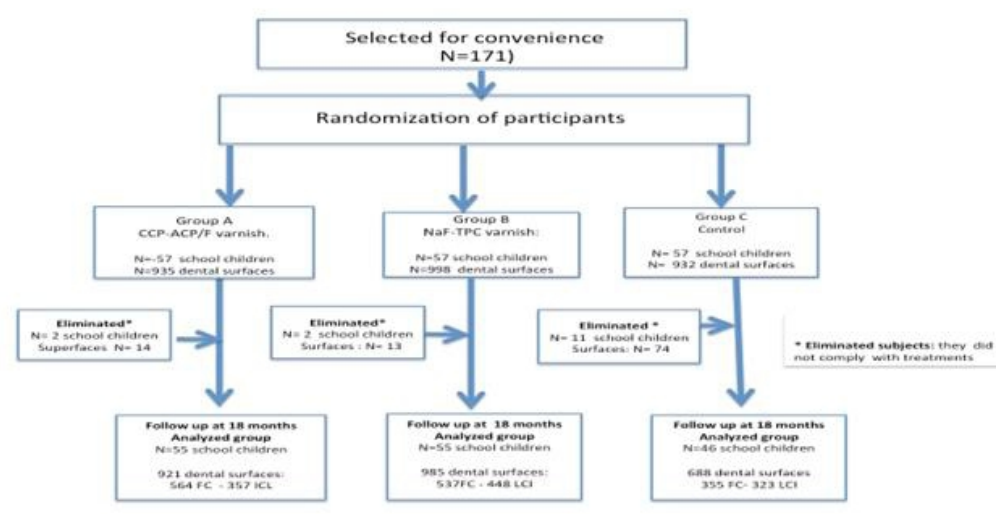

Fig.1 FLOW DIAGRAM THROUGH THE CLINICAL TRIAL

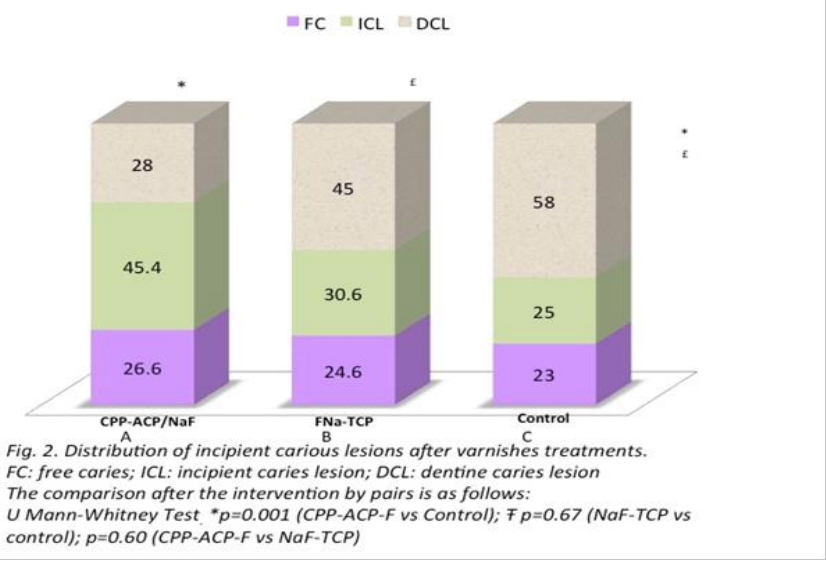

\section{References:}

1. Abanto, JA., Bonecker, M., \& Raggio, DP. (2011). Impact of oral diseases and oral disorders on oral health related quality life in preschool children. Community Dent Oral Epidemiolol , 39 (2), 10514.

2. Alamoudi, SA., Pani, SC., \& Alomari, M. (2013). The effect of the addition of tricalcium phosphate to $5 \%$ sodion varnishes on the microhardness of enamel of primary teeth. Int $J$ Dent . doi:101155/2013/486358.

3. Arruda, AO., Senthamarai Kannan, R., Inglehart, MR., Rezende, CT., \& Sohn, W. (2012). Effect of 5\% fluoride varnish application among 
school children in rural Brazil a randomized controlled trial. Community Dent Oral Epidemiol , 4 (40), 267-71.

4. Braga, MM., Oliveira, LB., Bonini, GA., Bönecker, M., \& Mendes, FM. (2009). Feasibility of the International Caries Detection and Assessment System (ICDAS-II) in epidemiological surveys and comparability with standard World Health Organization criteria. Caries Res , 49 (4), 245-9

5. Butcher, NJ., Mew, E., \& Saeed, L. (2019). Guidance for reporting outcomes in clinical trials: scoping review protocol. BMJ Open , 19 (9), 2. Doi: 10.1136bmjopen-2018-023001.

6. Chen, F. \& Wang, D. (2010). Novel technologies for the prevention and treatment of dental caries: a patent survey. Expert Opin Ther Pat, 20 (5), 661-94.

7. Clinpro, TM. (2015). White Varnish keeps getting better-now with TCP.

Avaible:

http://multimedia.3m.com/mws/media/6547030/clinpro-whitevarnish-extraprotectionfolder.pdf?fn=Clinpro_White_Varnish_F.pdf . ClinproTM White Varnish keeps getting better-now with TCP

8. Cochrane, N. \& Reynolds, E. (2012). Calcium phosphopeptidesmechanism of action and evidence for clinical efficacy. Adv Dent Res , 24 (2), 41-7.

9. Elkassas, D. \& Arafa, A. (2014). Remineralizing efficacy of different calcium-phosphate and fluoride based delivery vehicles on artificial caries like enamel lesions. J Dent. , 42 (4), 466-77.

10. Espinosa, R., Bayardo, R., Mercado, A., Ceja, I., \& Igarashi, C. B. (2014). Effect of fluorinated systems on the remineralization of incipient carious lesions of enamel, in situ study. Dental Operative and Biomaterials , 3 (1), 14-21.

11. Fearsthone, JD. \& Domejean, G. (2012). The role of remineralizing and anticaries management. Adv Dent Res, 24 (2), 28-31.

12. Hug, NL., Myroforidis, H., Cross, KJ., Stanton, DP., Verth, PD., Ward, BR., \& Reynols, EC. (2016). The interactions of CPP-ACP with saliva. Int $\mathrm{J} \quad \mathrm{MOl}$ Sci $, 17(6), \quad 995$ available: https://www.ncbi.nlm.nih.gov/pmc/articles/PMC4926448/pdf/ijms17-00915.pdf .

13. Juárez-López, LA., Hernández, D., Hernández, JC., Jiménez, D., \& Molina, N H. (2014). Preventive and remineralizing effect of incipient caries of casein phosphopeptide amorphous calcium phosphate. RIC, 66 (2), 144-51.

14. Marinho, VC., Worthington, HV., Walsh, T., \& Clarkson, JE. (2013). Fluoride varnishes for preventing dental caries in children and 
adolescents (Review). Database of Syst Rev, Issue 7: CD002279. doi: 10.1002 / 14651858.

15. Nongonierma, AB.F.R. (2012). Biofunctional properties of caseinophos phopeptides in the oral cavity. Caries Res, 46(3):234-67.

16. Ogodescu, A., Igna, A., \& Magda, L. (2017). Unconventional noninvasive diagnostic techniques and treatment of whitw spot lesions in paediatric dentistry and orthodontics. European scientific journal, doi:10.19044esj.2017.v17,n15p339.

17. O'Leary, TJ., Drake, RB., \& Naylor, JE. (1972). The plaque control record. J Periodontol , 43 (1), 38-42.

18. Pitts, NB. \& Ekstrand, KR. (2013). International Caries Detection and Assessment System (ICDAS) and its International Caries Classification and Management System (ICCMS) - methods for staging of the caries process and enabling dentists to manage caries. . Community Dent Oral Epidemiol , 41 (1), e41-52.

19. Schwendicke, F., Splieth, C., Murray, W., Reda, S., Stolpe, M., \& Foster, L. S. (2018). Cost- effectiviness of caries preventive fluoride varnish applications in clinic settings among patiens of low, moderate and high risk. Community Dent Oral Epidemiol , 46 (1), 9-16.

20. Shemehorm, BR., Wood, GD., McHale, W., \& Winston, AE. (2011). Comparison of fluoride uptake into tooth enamel from two fluoride varnishes containing different calcium phosphate source. J Clin Dent , 22 (2),51-4.

21. Rirattanapong, P., Vongsavan, K., Saengsirinavin, C., \& Pornmahala, T V. (2014). Effect of fluoride varnishes containing Tri-calcium phosphate sources on remineralization of initial primary enamel lesions. Southeast Asian J Trop Med Public Health, (45), 499-504.

22. SIVEPAB (2015). Outcome of the Epidemiological Surveillance System of Oral Pathologies. SIVEPAB. 10 years observed the oral health of Mexicans. available at: http://187.191.75.115/gobmx/salud/documentos/info_sivepab/SIVEP AB_10moani v.pdf.

23. Thimmaiah, C., Shetty, P., Shetty, SB., Natarajan, S., \& Thomas, NA. (2019). Comparative analysis of the remineralization potencial of CPP-ACP and fluoride, Tri calcium phosphate and nanohydroxyapatite usingSEM/EDX: an vitro study. J Clin Exp Dent, 11 (12), e1120 - e1126. https://doi.org/10.4317/jced.55941

24. Walczak, M. \& Turska-Szybka, A. (2017). The efficacy of fluoride varnishes containing different calcium phosphate compounds. Fluoride , 50 (1), 151-60. 